\title{
Mulemba
}

Revista Angolana de Ciências Sociais

\section{A unidade cultural da África Negra: uma reflexão de grande alcance teórico e metodológico}

Américo Kwononoka

\section{(2) OpenEdition}

Edição electrónica

URL: http://journals.openedition.org/mulemba/434

DOI: $10.4000 /$ mulemba.434

ISSN: 2520-0305

Editora

Edições Pedago

Edição impressa

Data de publição: 1 maio 2015

Paginação: 493-499

ISSN: 2182-6471

\section{Refêrencia eletrónica}

Américo Kwononoka, «A unidade cultural da África Negra: uma reflexão de grande alcance teórico e

metodológico», Mulemba [Online], 5 (9) | 2015, posto online no dia 22 novembro 2016, consultado o 27 janeiro 2021. URL: http://journals.openedition.org/mulemba/434 ; DOI: https://doi.org/10.4000/

mulemba.434

Este documento foi criado de forma automática no dia 27 janeiro 2021.

Tous droits réservés 


\title{
A unidade cultural da África Negra: uma reflexão de grande alcance teórico e metodológico
}

\author{
Américo Kwononoka
}

\section{NOTA DO AUTOR}

Texto da apresentação pública da tradução portuguesa da obra de Cheikh Anta Diop, A unidade cultural da África Negra. Esferas do patriarcado e do matriarcado na antiguidade clássica (Tradução de Sílvia Cunha Neto, revisão de Susana Ramos. Luanda, Edições Mulemba; Ramada, Edições Pedago, 2014, 194p. [«Reler África»]), lido durante o «Ciclo de actividades em alusão ao Dia de África», no Anfiteatro principal da Faculdade de Ciências Sociais (FCS) da Universidade Agostinho Neto (UAN), em Luanda, em 25 de Maio de 2015.

1 Agradeço ao Decano da Faculdade de Ciências Sociais (FCS) da Universidade Agostinho Neto (UAN), Prof. Doutor Víctor Kajibanga, pelo convite que gentilmente me fez para, nesta ocasião em que comemoramos mais um aniversário do Dia da África, apresentar a obra A unidade cultural da África Negra, e, com isso, homenagear o seu autor, o eminente pesquisador senegalês, mas de estatura mundial, que é Cheikh Anta Diop. Apresentar a obra de uma das mais importantes sumidades e proeminentes vozes científicas do mundo em geral e de África em particular, constitui para mim uma subida honra, mas também um grande atrevimento, pela minha pequenez diante desta comunidade académica e de outras entidades presentes neste acto alusivo ao dia do continente africano, berço de origem do Homo.

2 Composta de sete capítulos e um total de 192 páginas, a obra tem como epicentro da abordagem, a crónica oposição do seu autor às ideias e teses antropológicas e históricas, que assentam numa perspectiva evolucionista do século XIX, em particular as de Johann Jakob Bachofen (1815-1881) e Lewis Henry Morgan (1818-1881). 
3 Estes cientistas sociais advogavam a passagem universal de regime de filiação uterina ou matrilinear para a filiação agnática ou patrilinear. 0 primeiro estudou o problema do matriarcado e da descendência matrilinear como primeiro estádio da cultura. Para ele, a sociedade humana teria começado por uma promiscuidade primitiva, na qual não existia qualquer organização nem social nem sexual, pelo que o pai não era conhecido, apenas a mãe que estava ligada fisicamente aos filhos. A descendência e a hereditariedade, defendia Bachofen, foram assim definidas segundo a linha materna e só mais tarde se passou aos estádios sucessivos de patriarcado e da descendência patrilinear.

4 Por sua vez Lewis Henry Morgan, baseado no sistema de parentesco encontrado entre os índios da América, aponta 4 tipos de família que se sucederam, a saber: a) a mais antiga, da promiscuidade primitiva no Havai; b) a chamada família punaluana como exógama (irmãs e primas casam com irmãos e primos vindos do exterior; c) a família sindiásmica, monogâmica mas matrilinear com facilidade do divórcio, mantendo os filhos no lado materno; d) família monogâmica patriarcal impossibilitada de se divorciar (a mulher vive em dependência total do marido).

5 Na sua obra System of consanguinity and afinity of human family de 1879, Morgan apontava, que «[...] Todos os homens de uma dada geração são casados com todas as mulheres da mesma geração; todos os "avós" e todas as "avós", etc., e por conseguinte, todos os irmãos e irmãs são casados emtre eles. [...]» (p. 17). Por outras palavras, ele opinava sobre a existência de «um sistema classificatório de parentesco em que um homem trata pai e mãe a todos os homens e mulheres da geração de seu pai e de sua mãe; e irmãos e irmãs ou filhos e filhas destes, é uma evidência de que as relações sexuais nessa sociedade foram em certa altura mais ou menos promíscua». Bachofen e Morgan afirmavam e defendiam a universalidade do matriarcado e a sua anterioridade, evoluindo mais tarde para a filiação e descendência patrilinear, opondo-se à extensão do patriarcado.

6 Friedrich Engels, um experiente analista de formação e tendência marxista, mostrandose convicto em demonstrar a historicidade do carácter provisório de todas as formas de organização política e social, serviu-se dos materiais de Bachofen e de Morgan para uma construção teórica cuja consistência não estava comprovada cientificamente pelo referido material. Até aqui procuramos ver a essência da abordagem da obra apresentada no Capítulo I, e que nos parece ser o invólucro e o epicentro das questões, que se ramificam para os restantes capítulos.

7 No Capítulo II, o autor faz uma apreciação crítica às teses dos evolucionistas e de Engels, demonstrando que não houve passagem universal de matriarcado para o patriarcado porque «a humanidade se dividiu originariamente em dois conjuntos geograficamente distintos, num propiciou o matriarcado e noutro o patriarcado $e$ os dois sistemas se reencontraram, disputando as diferentes sociedades humanas, ora se sobrepuseram ora justapuseram-se». Por outras palavras, um sistema de filiação não constitui um desenvolvimento contínuo do outro. A tendência é a compenetração dos dois sistemas originariamente autónomos, sobressaindo aquele que a antropologia designa por dupla filiação unilinear ou a filiação cognática (bilateral ou indiferenciada). 0 autor compara os diferentes berços geograficamente distintos (Eurásia e Africano) uns propícios à vida nómada e outros inclinados à agricultura e declara que é impossível que tenham engendrado os mesmos tipos de organização social. Dá alguns exemplos sobre o culto aos antepassados, cremação e a cinza, o culto do fogo, os cultos aos mortos, entre outros em contextos diferentes. 
O Capítulo III caracteriza diferentes berços da história do patriarcado e do matriarcado, demonstrando que durante o I milénio antes da nossa era, muitos países de África já poderiam ser governados por mulheres, tal como a Etiópia pela rainha Candance, contemporânea de César Augusto, cujo prestígio foi de tal modo elevado que todas as rainhas que lhe sucederam adoptaram o seu nome. O Egipto, através do mito da DeusaMãe do trigo, criadora da verdura, senhora do pão, da cerveja e da abundância, exaltava religiosamente uma mulher. $\mathrm{O}$ autor aborda a questão do casamento, que no Egipto foi sempre monogâmico, excepto a família real e os dignatários da corte que praticavam a poligamia (é quando um indivíduo toma para si vários parceiros de sexo oposto e pode ser poliandria ou poliginia. Para o nosso caso é a poliginia, que é uma forma de casamento polígamo em que um homem toma para si várias mulheres como esposas legais e legítimas) segundo o grau ou a natureza da sua fortuna e que emergiu como um luxo que foi transplantado na vida familiar e social. Nas representações esculturais e pictóricas do antigo Egipto, a monogamia popular é comprovada pelos numerosos casais representados.

9 Contrariamente a essa forma de casamento verificada no Egipto, Cheikh Anta Diop afirma que já «no berço nórdico, a poligamia era comum na aristocracia germânica do tempo do Tácito, na Grécia, na época de Agamémnon, em toda a Ásia, no Egipto na familia faraónica e na dos dignitários da corte». Por outras palavras, estas ilações permitem observar que, contrariamente ao que advogavam os evolucionistas, a monogamia não resulta da evolução da poligamia. Este assunto está retomado no capítulo seguinte.

Relativamente ao tema central, as populações da África Negra, entre outras as do Mali, do Senegal, do Ghana, as da antiga Bechuanalândia (actual Botswana), do Sul da África e os Bantu da África Central, foram sempre matrilineares. Com a islamização, um factor externo e não um processo de evolução interna, a maior parte das populações que na Idade Média eram matrilineares, tornaram-se aparentemente patrilineares.

11 O Capítulo IV continua este assunto, analisando a problemática dos regimes de filiação. $\mathrm{O}$ autor justifica que as origens matriarcais da sociedade são atenuadas pela transformação e mudança paulatina para o patriarcado africano com base em factores externos, assinalados, por exemplo, pela penetração do Islamismo e do Cristianismo e pela presença temporária da Europa (colonialismo) em África. $\mathrm{O}$ africano islamizado é automaticamente dominado pelo regime patriarcal, sobretudo no que concerne à herança dos bens; o mesmo sucede com os cristãos, protestantes ou católicos, em que o domínio do homem é imposto. Outro elemento exógeno na configuração ou formatação de novos regimes de filiação foi a legislação colonial que tendia a atribuir um estatuto da herança por via patrilinear.

12 As exigências do contacto e da compenetração cultural, fazem com que alguns africanos se sintam cada vez mais próximos do seu filho do que do seu sobrinho. Porém, em algumas comunidades com pouco contacto com a Europa, o filho não tem nada, mas o sobrinho tem tudo, uma perspectiva do avunculato (relação especial entre o irmão da mãe e o sobrinho, seu sucessor predilecto).

13 O Capítulo V é dedicado à comparação dos outros aspectos das culturas nórdica (Europa) e Meridional (África) fora do âmbito familiar. Um dos aspectos consiste em saber qual dos berços tinha, em primeiro lugar, oferecido à mulher a possibilidade de se emancipar. Outro aspecto é a origem do Estado. As vidas sedentária e nómada deram origem a duas formas diferentes de estados, tal como, por exemplo, o colectivismo que é uma consequência lógica do sedentarismo agrícola. 
14 No Vale do Nilo, no norte de África, a estrutura política exigia da população empreendimentos e uma actividade comum a todos os Nomos e a todas as cidade, face ao fenómeno natural, como as cheias do rio. Era exigido um Estado forte, que transcendesse na unificação administrativa e cultural, a noção de Estado e de Nação (vocação imperial do Médio Oriente segundo André Aymard, citado por Cheikh Anta Diop, na p. 129). Segundo o autor, o sentimento patriótico, é um sentimento de orgulho nacional; o indivíduo é subordinado à colectividade, uma vez que é do bem público que depende o bem individual e o direito privado subordina-se ao direito público.

15 Já na Europa, entre os arianos, a vida nómada fazia da família uma entidade absoluta, autónoma, independente em todas as suas determinações, auto-suficiente do ponto de vista económico e de outros. $O$ autor cita Fustel de Coulanges, que demonstra, na p. 131, que «o direito privado nos arianos, é anterior à fundação da cidade, pelo que durante longo tempo, o Estado (em Roma e na Grécia) não tinha qualquer poder para intervir na vida privada das familias. Podia-se matar um filho, uma esposa, um escravo ou vendê-los, não constituia crime face ao Estado que era a Cidade, quer dizer, o público terminava à porta das casas». É o domínio do individualismo do berço nórdico.

16 Entretanto, o capítulo em análise aborda e compara ainda, a questão da realeza que vai transcender a um carácter sobrenatural, a religião cuja diferença não é menos significativa entre as concepções nórdica e meridional.

17 O Capítulo VI aponta a possibilidade histórica ou não de confrontar ou comparar a África negra actual e do Egipto antigo. Aqui chama a atenção do erro que os historiadores cometem em imaginar o passado de acordo com o presente. As comparações entre o Egipto antigo e a África Negra actual só serão consideradas objectivas e científicas na medida em que for possível demonstrar que se evitou essa tendência. $\mathrm{O}$ autor analisa ainda o sistema de castas que dominam a sociedade africana e que conserva a estrutura e se opõe às perturbações, dando exemplo do caso africano em que a casta inferior se recusa ser introduzida numa casta superior caso só os interesses materiais estivessem em jogo. Contrariamente ao proletário que adoptaria com agrado o lugar do patrão.

18 A proximidade gramatical das línguas africanas actuais e do Egipto antigo da XVIII dinastia, demonstra que a comparação não é ilusória, mas legítima, pois o vocabulário de algumas línguas africanas, tal como por exemplo o wolof, poderia provir de uma antiguidade extremamente recuada.

19 No Capítulo VII o autor concentra a sua atenção aos tipos de cultos dos antepassados na perspectiva indo-europeia e na de África. Nesta, o culto realiza-se através da partilha da refeição fúnebre dedicada ao seu respectivo antepassado, da invocação do nome totémico que cada família possui como garante da sua protecção, em geral de um animal.

20 Finalmente, o autor demonstra com forte argumento que os contextos nórdico e meridional diferentes do ponto de vista geográfico, económico, cultural e do estilo de vida, não possibilitaram a criação de uma vereda evolutiva para a universalidade cultural, pois os seus protagonistas são de perspectivas diferentes.

21 A Unidade cultural da África Negra, título da presente obra, caracteriza-se na sua generalidade, pela análise da família e filiação matrilineares, pela criação do Estado Território (em oposição à Cidade-Estado ariano), pela emancipação da mulher na vida doméstica, por uma espécie de colectivismo social, chegando até à despreocupação em 
relação ao futuro. Caracteriza-se também por uma solidariedade material de direito para cada indivíduo (o que faz com que a miséria material ou moral seja desconhecida até aos nossos dias; é certo que existem pessoas pobres, porém ninguém se sente só, ninguém está angustiado).

$\mathrm{Na}$ esfera moral, percebe-se um ideal de paz, justiça, de bondade, um optimismo que elimina a noção de culpa ou de pecado original nas criações religiosas. Na literatura, o género predilecto é o narrativo - o romance, o conto, a fábula e a comédia. Tudo isso é contrário à perspectiva moral nórdica antiga.

Não restam dúvidas que está em vossas mãos um grande instrumento histórico, antropológico e linguístico, um monopólio e manancial de informações com valores perenes sobre a antiguidade e modernidade da África, o berço do Homo que em muito contribuiu para a civilização universal.

\section{AUTOR}

\section{AMÉRICO KWONONOKA}

amerikwononoka@hotmail.com

Docente do Instituto Superior João Paulo II da Universidade Católica de Angola (UCAN) e doutorando em Ciências Sociais pela Faculdade de Ciências Sociais (FCS) da Universidade Agostinho Neto (UAN).

É docente do Instituto Superior João Paulo II, da Universidade Católica de Angola (UCAN). É licenciado em Ciências da Educação, opção História e Mestre em História de Angola pelo Instituto Superior de Ciências da Educação (ISCED) de Luanda e doutorando em Ciências Sociais, na opção Antropologia, pela Faculdade de Ciências Sociais (FCS) da Universidade Agostinho Neto (UAN). Tem estudos e comunicações publicados em livros colectivos e em revistas, das quais se destaca: «Visão antropológica do exercício do poder tradicional. O caso do Ohamba Mungambwe», in I Encontro Nacional sobre a Autoridade Tradicional em Angola, Luanda, Ministério da Administração do Território e Nzila, 2003, pp. 141-149; Os Povos do Leste de Angola. Luanda, Expo-Aichi Japão, 2005; «Subsídios históricos sobre o papel da autoridade tradicional em Angola, in Mensagem - Revista Angolana de Cultura (Luanda), n.ำ1, 2007; «Diversidade, educação e interculturalidade como fundamentos para a consolidação da Nação Angolana», in Mulemba Revista Angolana de Ciências Sociais (Luanda), vol. II, n.ํ 3, Maio de 2012, pp. 129-146; «Algumas actividades económicas tradicionais da região do Leste de Angola», in Memória viva da cultura da região Leste de Angola (2012); «Autoridade tradicional e questões de etnicidade em Angola», in Boaventura de Sousa Santos e José Octávio Serra Van-Dúnem (orgs.), Sociedade e Estado em construção. Desafios do Direito e da Democracia em Angola. Luanda e justiça: pluralismo jurídico numa sociedade em transformação, volume I. Coimbra, Almedina, 2012, pp. 315-339. É deputado a Assembleia Nacional da República de Angola. 